\title{
Bagels and Steak: A Mind Genomics Cartography of an 'Alpha vs. Omega' of Dining
}

\author{
Howard Moskowitz $^{1 *}$, Martin Braun ${ }^{2}$, Sue Henderson ${ }^{3}$ and Joann Mazzio ${ }^{4}$ \\ ${ }^{1}$ WICE, World Institute of Competitive Excellence, New York, USA \\ ${ }^{2}$ Queens College, City University of New York, New York, USA \\ ${ }^{3}$ New Jersey City University, New Jersey, USA \\ ${ }^{4}$ Independent Researcher, New York, USA \\ *Corresponding author: Howard Moskowitz, WICE, World Institute of Competitive Excellence, New York, USA; Email: mjihrm@gmail.com
}

Received: December 23, 2021; Accepted: December 30, 2021; Published: January 07, 2022

\begin{abstract}
The paper presents two Mind Genomics cartographies of restaurants, a morning-oriented bagel shop and an evening-oriented steak house. Thirtysix elements for each restaurant, text appearing in different advertisements, were selected, edited if necessary, and then combined into small, easy to read vignettes, prescribed by an underlying experimental design. The ratings were assigned to the vignettes, the first focusing on interest, the second requiring the selection of one of five feeling. For the bagel shop two mind-sets emerged, not strongly different, but providing different emphases on two themes: the experience and the product, respectively. For the steak house three dramatically different mind-sets emerged, focusing on product quality, on selection and service, and on ambiance, respectively. The emotional profiles differed by restaurant. The bagel shop did not elicit strong emotional linkages with elements, whereas the steak house elicited linkages to the feelings of confident and uncertain, respectively. The ability to create deep information about the 'ordinary' through simple online experimentation suggests the potential creation of large-scale, intercomparable databases on facets of everyday life, using scientific methods, at a rapid pace, at low cost, with scalability across cultures and over time.
\end{abstract}

\section{Background}

Studies of the customer experience are becoming increasingly popular today. One can scarcely engage in a commercial transaction without the corporate representative warning that there may be a follow-up survey about the experience, and would the customer or client be kind enough to up-rate the corporate representative when instructed to assign the rating of 'experience.'

This 'mania' to evaluate the experience has emerged from the competitive landscape, where the experience itself has become as important as the product being purchased. When the experience is the product, such as restaurants, knowing what makes customers satisfied/happy versus dissatisfied/unhappy is of great important. The conventional wisdom is that one should treat one's customers right, or else the competitors will.

In the spirit of understand the dimensions of daily experience was born Mind Genomics The objective was and remains to study the experience of the everyday, not so much in the purity of conventional research which isolates a variable to understand it, but rather in the spirit of the random events of daily experience.

In the world of customer wishes and customer experience, Mind Genomics emerges from a decades long effort to understand the relation between what a product or an experience 'comprises' and how people react to the product or experience. in other words, what makes a good experience? What specific features can be combined to improve experience?. The answer to the foregoing questions have has more than academic value to build knowledge. The answer to 'what makes a good experience' is part of the key to business success.

\section{Insights - A Plethora of Unknown Knowns}

Part of the history of Mind Genomics emerged from the world of consumer research and the so-called 'insights business.' One way to look at the consumer research and restaurants or indeed almost any topic, is by the nature of the so-called insights which emerge. With their history in sociology and political polling, consumer researchers often excel in measuring external behavior, whether directly, or culling different sources of information and creating from that a model of what might be happening in the mind of consumers. These are consumer trends, evaluated from the outside in, from observing behavior, or from asking questions, uncovering patterns.

What consumer researchers do not know, however, is what messages really work and why they work, viz. the insight out. Presumably people respond to messages, either to patronize a restaurant (the focus here) to buy a product, hire a service, and so forth. Consumer researchers can measure the responses to existing ideas, doing so in any number of ways, and with many tools, ranging from simple polls to in-depth discussion. What is not known, however, is the reaction to specific messages. These are 'known unknowns', in the words of former Secretary of Defense, Donald H. Rumsfeld. 
It is the systematic study of these messages, using disciplines including experimental design, statistical modeling, and clustering which define the lineaments, the outward aspects of this emerging science, Mind Genomics. The specific objective is to understand the nature of decision making for topics of the everyday, using the pattern of responses to actual messages of real meaning given at by the source of the topic [1]. In other words, understand the topic, say restaurants, not from 30,000 feet, using abstractions, but rather from responses to and judgments of the actual messages that an individual might encounter when reading about the restaurants.

\section{Explicating the Process and Demonstrating with the Results from Two Teams of Students}

The Mind Genomics system is templated, allowing anyone to become a researcher. The studies reported below represent the contributions of students to knowledge about restaurants, specifically a bagel shop versus a steakhouse. Both studies reveal the power of insights that are available to virtually anyone willing to think about a topic, to do 'background' research using the web on a specific topic, and then to execute a small evaluation with Mind Genomics, involving 36 messages, 50 respondents in a study taking 60 minutes to field with complete results with 5-10 minutes after the last respondent has completed the interview.

By way of background the study was conducted as part of a program at Queens College of the City University of New York, run by author Dr. Martin Braun and author Dr. Sue Henderson. The studies were part of the Queens College effort to introduce new pedagogies to students who declared themselves to be not 'science material', but had to take a mathematics course to satisfy the curriculum requirements. Math 110 was the result, a combination of experimentation, statistics, and an application to create excitement among the students regarding mathematics and research, and an item for their personal portfolio.

Each group met, selected a topic. During two separate years, and two separate classes, the topics of bagel shop and steak houses were selected, by different students. The objective was to apply the Mind Genomics thinking to studying these two topics. The students were encouraged to read about the topic they selected, especially using the Internet, and then with the messages that they gleaned from the Internet, and their own imagination, they were to run a study with 50 respondents, funded by Queens College.

The efforts, done 2011-2012, eventuated into a series of studies with profound implications, as shown below. The two studies, bagel shop and steak house, were done on topics where there is a great deal of information available about different offerings by restaurants, and news stories about one or another restaurant appearing in the popular press. Based upon Google(r), and a search at the time of this writing (Fall, 20201), there are a remarkable 8.8 million hits for bagel shop and an even more remarkable 26.3 million hits for steakhouse. Surprisingly, however was almost nothing about these restaurants in the scientific press, as shown by a search of Google Scholar(r). That is, the topic of dining and eating is relevant to academic researchers, but only in the context of 'general rules', with practical, every day, 'cognitively meaningful' experience not a key topic of the research. The topic of bagel shops, for example, is of interest to sociology as it compares to bodegas [2], and of interest as an example of understanding economic behavior [3,4]. But the topic of bagel shops in and of itself is ignored, perhaps because until now there has been no structure in which to embed current knowledge and create new knowledge.

We present the two studies intertwined, to show the differences between an eating place that is casual, familiar, and oriented to mornings, versus an evening higher sale restaurant. The research process was virtually the same for both. The results provide a sense of what can be quickly learned about messaging, simply by doing a deconstruction of messages provided by current offerors, coupled with imagination, and implemented in a few hours.

\section{Step 1: Decide the Topic, Create a Set of Questions Which 'Unfold the Restaurant', and for Each Question Provide a Set of 'Answers or Simple Phrases}

In today's (2021) version of Mind Genomics, the number of questions and the number of answers to each question has been trimmed to four questions, four answers to each question, generating 24 vignettes, rated on one scale, and requiring a field execution of 3-4 minutes at most, reasonable in a period where time is a valuable commodity. When these studies were run, 2011-2012, there was less time pressure, so the studies were larger, comprising six questions, six answers per question, generating 48 vignettes, and two rating scales, requiring 17 minutes.

Table 1 shows the elements for the bagel study, Table 2 shows the elements for the steak study. It is important emphasize that most, not all, of the elements were taken from existing messaging. Thus, the Mind Genomics 'experiments' reported here can reveal the degree to which the existing restaurants used demonstrably strong-performing elements, and, perhaps unexpectedly, selected elements appealing to different mind-sets existing within the restaurant's clientele. The assumption is that the material appearing in advertisements represents 'vetted selling points.'

\section{Step 2: Combine the Elements (Answers, Messages) into Small, Easy to Read Combinations, Using an Experimental Design}

A hallmark of Mind Genomics is the nature of the stimulus. The test stimuli are combinations of elements. The combinations are strictly prescribed, according to an underlying structure known as an experimental design [5]. Experimental designs are well accepted in science. They prescribe combinations of variables. It the response to these combinations which is of interest. The response will be deconstructed into the contributions of the separate elements.

The use of combinations rather than of single elements emerges from a fundamental difference between the science of Mind Genomics to understand the psychology of the everyday, and other areas of psychology in particular and science in general, which focus on testing stimuli in as pure a form as possible. That is, the typical psychological approach would be to test all 36 elements, one element at a time, instructing the respondent to rate the single element. In 
Howard Moskowitz (2022) Bagels and Steak: A Mind Genomics Cartography of an 'Alpha vs. Omega' of Dining

Table 1: Elements for the bagel store study.

\begin{tabular}{|c|c|}
\hline & Question A: What is location and the ambience? \\
\hline Al & Easily available for commuters \\
\hline A2 & Convenient walking location \\
\hline A3 & Convenient drive though \\
\hline A4 & Comfortable ambience \\
\hline A5 & Nice music \\
\hline \multirow[t]{2}{*}{ A6 } & Many locations available \\
\hline & Question B: What are 'good for you' features? \\
\hline B1 & All bagels are highly nutritious \\
\hline B2 & includes vitamins and minerals \\
\hline B3 & Bagels are all-organic \\
\hline B4 & All bagels are made fresh \\
\hline B5 & No preservatives in our bagels \\
\hline \multirow[t]{2}{*}{ B6 } & All spreads are healthy \\
\hline & Question C: What are price specials? \\
\hline $\mathrm{C} 1$ & The best ingredients for the lowest prices \\
\hline $\mathrm{C} 2$ & includes discounts \\
\hline $\mathrm{C} 3$ & Get a free mug with a dozen bagels \\
\hline $\mathrm{C} 4$ & Gift cards available \\
\hline C5 & Affordable prices \\
\hline \multirow[t]{2}{*}{ C6 } & Buy ten get two free \\
\hline & Question D: Describe the sensory experience \\
\hline D1 & Delicious in many flavors \\
\hline D2 & Bagels are a high quality \\
\hline D3 & Highest rated bagels in the state \\
\hline D4 & Available in every flavor and color \\
\hline D5 & Savory and melts in your mouth \\
\hline \multirow[t]{2}{*}{ D6 } & Innovative bagel technology to create the best taste \\
\hline & Question E: Describe flavor of bagels and spreads \\
\hline E1 & Made from high-quality ingredients \\
\hline E2 & All organic ingredients for the many spreads \\
\hline E3 & Mix and match for your favorite personal combination \\
\hline E4 & Help create your own flavor with our new flavor creator \\
\hline E5 & Hundreds of spreads to choose from \\
\hline \multirow[t]{2}{*}{ E6 } & Free toasting available with spread purchase \\
\hline & Question F: Describe delivery features \\
\hline F1 & Order fresh bagels anytime \\
\hline $\mathrm{F} 2$ & Order one dozen bagels for only $\$ 6$ \\
\hline F3 & Order before $6 \mathrm{pm}$ for same day shipping \\
\hline $\mathrm{F} 4$ & Order gift boxes for any occasion \\
\hline F5 & Local delivery in only $30 \mathrm{~min}$ \\
\hline F6 & Free shipping with any purchase over $\$ 15$ \\
\hline
\end{tabular}

Table 2: Elements for the steak study.

\begin{tabular}{|c|c|}
\hline & Question A: What is one product description that would gain attention \\
\hline A1 & We have the biggest portion sizes around. \\
\hline A2 & $\begin{array}{l}\text { Our menu includes more than just steaks...variety of delicious chicken, fish and } \\
\text { vegetarian options }\end{array}$ \\
\hline A3 & Come try our legendary $48 \mathrm{oz}$ porter house and join the carnivore club \\
\hline A4 & Many great desert options made from our world-renowned pastry chef \\
\hline A5 & Zagat rating of best beef wellington in the city \\
\hline \multirow[t]{2}{*}{ A6 } & $\begin{array}{l}\text { All our food is cooked with fresh grown material and all our steaks are USDA } \\
\text { prime approved steaks }\end{array}$ \\
\hline & Question B: Describe the interaction with the staff (nonfood) \\
\hline B1 & Save time with our valet parking. Our staff offers service with a smile \\
\hline B2 & Our staff offers service with a smile \\
\hline B3 & For your convenience book any reservation online \\
\hline B4 & We offer a private room for up to 50 guests \\
\hline B5 & Coat checking for the convenience of space at the table \\
\hline \multirow[t]{2}{*}{ B6 } & All waiters are veterans in the business \\
\hline & Question C: Describe other features such as alcohols, seasonal decorations, etc. \\
\hline $\mathrm{C} 1$ & A large selection of imported and domestic beers on tap \\
\hline $\mathrm{C} 2$ & We offer a huge selection of aged wine \\
\hline $\mathrm{C} 3$ & Come eat at the bar each night 7-9 p.m. for our happy hour discounts \\
\hline $\mathrm{C} 4$ & Enjoy a drink while you wait for your table \\
\hline $\mathrm{C} 5$ & Get into the holiday spirit with our seasonal decorations \\
\hline \multirow[t]{2}{*}{ C6 } & Since opening our restaurant has been rated top in the city for cleanliness \\
\hline & Question D: Where is the restaurant located \\
\hline D1 & Located in the heart of the city \\
\hline D2 & Conveniently located to subway lines \\
\hline D3 & Show your ticket stub from any nearby theaters to receive discounts \\
\hline D4 & Located near the financial sector of town \\
\hline D5 & Located a block away from the stadium \\
\hline \multirow[t]{2}{*}{ D6 } & Conveniently located a half mile off the interstate \\
\hline & Question E: Describe an experience in emotional terms \\
\hline E1 & Going on a date...enjoy our quiet child-free sections after 9 p.m. \\
\hline E2 & Lightly colored rooms to satisfy eloquent dining \\
\hline E3 & Dress comfortable while enjoying our casual dining \\
\hline $\mathrm{E} 4$ & Start off your romantic evening with a candlelight dinner \\
\hline E5 & Fresh flowers on each table to satisfy your senses \\
\hline \multirow[t]{2}{*}{ E6 } & Keep warm while waiting for your table near our fireplace \\
\hline & Question F: Describe other features beyond food and service \\
\hline $\mathrm{F} 1$ & Live singer every Tuesday night \\
\hline F2 & Enjoy a steak while cheering on the home team \\
\hline F3 & Offers a dance floor to spice up the night \\
\hline F4 & Jazz bands perform each Friday and Saturday night. \\
\hline F5 & Learn how to cook like our chefs...come to a cooking class in the afternoons \\
\hline F6 & Comedy shows are available \\
\hline
\end{tabular}


contrast, the Mind Genomics approach focuses on responses to combinations, presenting stimuli in the form shown in Figure 1. The vignette comprises four elements, not one. The respondent cannot find the 'right answer', so the respondent settles for being honest rather than being 'right'.

At first, the approach just stated above does not seem to make sense. It would seem that the four elements would fight with each other to drive the rating, whereas in the typical research approach attention is paid to each element one at a time. It is precisely the fact that the combinations resemble the type of information encountered in the daily, ordinary world, which makes Mind Genomics 'work.' People easily 'navigate' their way through a world of compound complexity, a world which mixes and matches various stimuli together in patterns which are erratic. What are the rules by which people evaluate these natural combinations, which they do in everyday behavior, whether the evaluation is to change the direction of their movement, stop to do something etc.

The goal of Mind Genomics is to understand these rules. Thus, the combinations tested by the respondent are created in a systematized fashion. The rules governing the precise combinations of elements are embedded in an experimental design [5]. The experimental design comprises a schematic which states which combinations are to be created. The experimental design DOES NOT prescribe the content of the combinations, but just the structure of those combinations.

Mind Genomics uses a set of experimental designs with these properties:

a. The nomenclature is question (i.e., variable), and answer (i.e., element)

b. Each question has the same number of answers

c. The answers (but not the questions) appear in the combinations, such as seen in Figure 1. d. The answers are statistically independent of each other, allowing the design to be analyzed by powerful statistical tools such as OLS (ordinary least-squares), and even with pairwise interactions when relevant.

e. The vignettes are incomplete. For this design of $6 \times 6$ (six questions, each question with six answers) the design prescribed 48 vignettes, 36 comprising four elements (two questions do not contribute to the vignette), and 12 comprising three elements (three questions do not contribute to the vignette).

f. The experimental design is works at the level of each respondent, so the data of a single respondent can be subject to the power analyses, such as OLS regression

g. Each respondent evaluates the same STRUCTURE of combinations, but the specific combinations are changed using a permutation scheme. That is, the mathematics is the same, but for each respondent the combinations are different. The permutation changes the assignment of each phrase to an element. This permutation is then used by the experimental design to create new, unique combinations. Table 3 shows an example of a permutation.

Table 3: Example of a permutation of six elements (A1-A6) for three respondents (R1-R3).

\begin{tabular}{|l|l|l|l|}
\hline R1 & R2 & R3 & Question A: What is location and the ambience? \\
\hline A1 & A3 & A4 & Easily available for commuters \\
\hline A2 & A1 & A5 & Convenient walking location \\
\hline A3 & A5 & A1 & Convenient drive though \\
\hline A4 & A4 & A6 & Comfortable ambience \\
\hline A5 & A6 & A2 & Nice music \\
\hline A6 & A2 & A3 & Many locations available \\
\hline
\end{tabular}

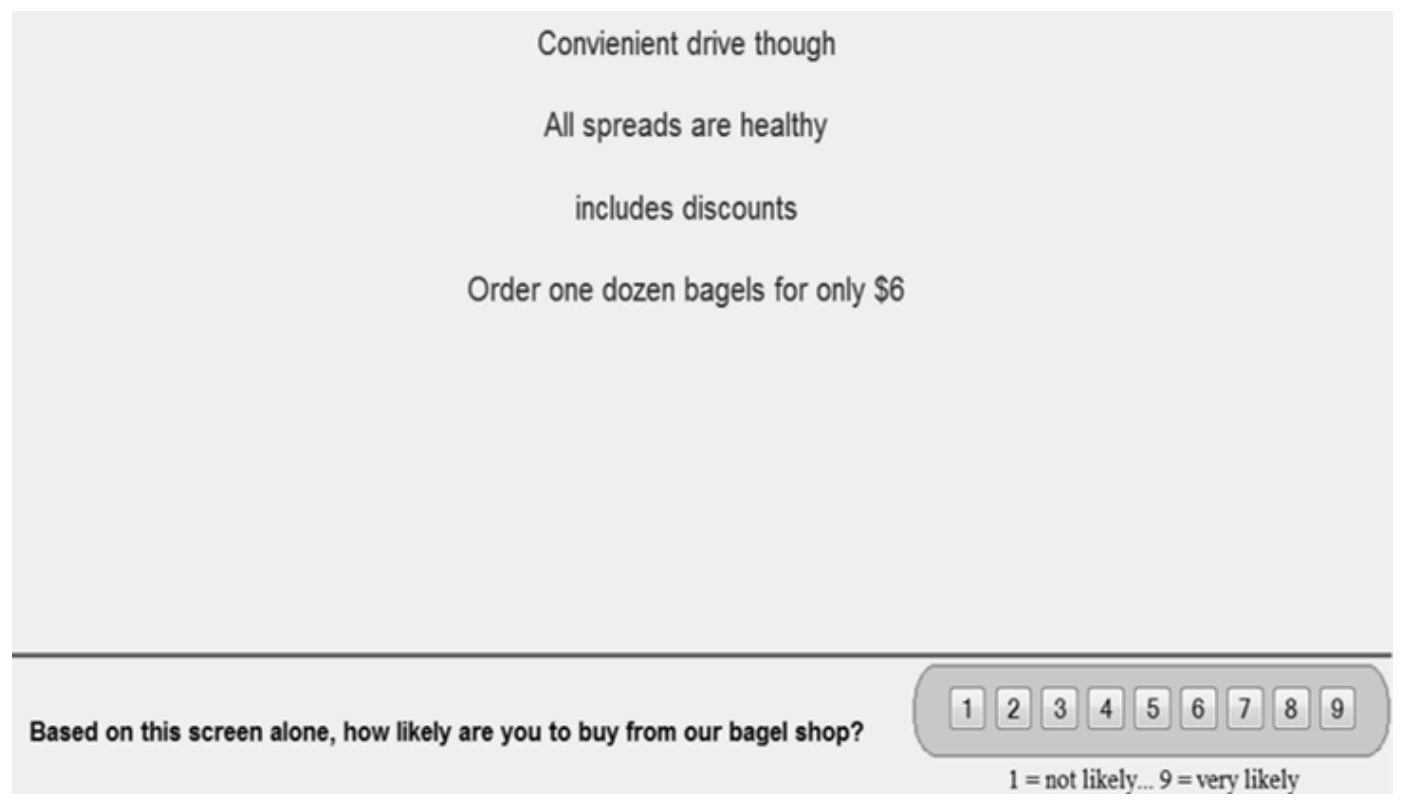

Figure 1: Four element vignette for a bagel shop, and the first rating scale at the bottom. 
h. It is important to realize that the permutations do not always work. [6] were able to patent the approach of permutation, and the different combinations which work. The viable combinations must be created empirically.

Figure 1 shows an example of a four-element vignette. The Mind Genomics program sets up the vignette, guided by the experimental design. There is no hint about the underlying questions. Rather, the respondent sees the combination ad rates the combinations on two scales below. The combination appear is rated on the first scale, rated on the second scale, and proceeds to the next combination.

Step 3: Present the respondent with the instructions (Figure 2), and then with the 48 vignettes, each of which is rated on two scales, shown in Figure 2.

The first scale is INTEREST (an evaluative criterion):

Bagel shop: Based on this screen alone, how likely are you to buy from our bagel shop ( $1=$ not likely .. 9=very likely)

Steakhouse: Based on this screen alone, how likely are you to come to our steakhouse ( $1=$ not likely ... 9=very likely)

The second scale is emotion (a choice across five feelings/ emotions), The feelings/emotions were selected by the students

\section{Bagel Shop Interested Uninterested Hungry Bored Excited}

\section{Steak House Eager Confident Uncertain Intimated Uninterested}

The orientation presents little background information, because the objective is to discover the elements which resonate, given the nature of the restaurant (bagel shop versus steak house). The usual practice of a Mind Genomics cartography is to present as little information as possible. Respondents do not need much information to form their judgments. The only situations when it is advisable to present more information are the where the background is important, such as a legal case.

At the end of the evaluation, the respondent completed a selfprofiling classification questionnaire detailing gender, age, education, food and restaurant attitudes and practices. For this paper we focus only on the total panel, and mind-sets emerging from the data.

Step 3: Transform the Data into a Form Readily Analyzable by OLS (Ordinary Least-Squares) Regression

Traditionally, managers using consumer data prefer simple statistics, such as no/yes. It is difficult for a manager to understand what an average actually 'means' in practical terms. Often, managers presented with data in the form of average ratings will ask 'what is a good average?' or 'what does the average really mean?' In some cases, such as the 9-point hedonic scale for liking, the researchers label every scale point, so that the manager presented with the data can refer to the labelled scale.

Mind Genomics follows a different tradition, inherited from consumer research and political polling. This different tradition was created by individuals who had to present data to managers, with neither the manager nor the researcher educated in science and in the business of scaling. The approach was elegantly simple. The researcher would divide the scale into two parts, choosing the dividing point by fiat. The process typically divided the 9-point scale into the lower half (1-6, coded ' 0 ') and the upper half (7-9, coded 100). The binary scale (0/100, $0 / 1$ ) is easy to understand, good or bad. For the data in this study, all ratings were transformed in that fashion. Afterwards a vanishingly small random number $(<10-5)$ was added to the ratings to ensure that the OLS regression would not 'crash', even if the respondent assigned all ratings either 1-6 (all coded 0), or 7-9 (all coded 100). This small prophylactic step is a standard practice for all scale data in Mind Genomics.

Today, you will be taking a survey regarding Bagel Shop.

You will be seeing different screens of situations regarding bagel shops.

Although they may seem similar, each screen combination is unique.

You will be asked two questions for each screen description of combinations:

1) Based on this screen alone, how likely are you to buy from our bagel shop? $1=$ not likely $\ldots 9$ = very likely

2) Based on this screen ALONE... How do you feel when you read these messages? 1 = Interested $2=$ Uninterested $3=$ Hungry $4=$ Bored $5=$ Excited

You will be asked the SAME 2 questions for each screen. Please rate each screen combination as a single unit.

It will take you 10 - 15 minutes to complete the study

You can track your progress on the top right of each screen.

Thank you for your participation in this important survey.

Please Click $\gg$ to Continue.

Figure 2: The orientation page for the bagel shop study. 
The second transformation was more complicated. The second rating question is a so-called nominal scale. The five numbers are placeholders only. They have no numerical meaning. The strategy to prepare the ratings from question \#2 was to create five new binary variables, one for each choice available in question \#2. For each case, each of the 48 vignettes, the one newly created binary variable corresponding to the emotion chosen was transformed to 100 . The four binary variables corresponding to the four feelings not chosen, were transformed to 0 . Once again the vanishingly small random number was added to the value 0 , to prevent crashes during the OLS regression.

\section{Step 4: Run Individual Level Models for Question \# 1 for Each Respondent, and Cluster the Respondents Using k-Means Clustering}

As noted above, the experimental design is valid at the level of a single respondent, even though each respondent evaluated 48 different vignettes. The property of complete design at the level of the individual respondent makes it possible to create an equation for each respondent relating the presence/absence of the elements A1 - F6 to the ratings $(0 / 100)$. The equation is written as:

Binary Dependent Variable $=\mathrm{k}_{0}+\mathrm{k}_{1}(\mathrm{~A} 1)+\mathrm{k}_{2}(\mathrm{~A} 2) \ldots \mathrm{k}_{36}(\mathrm{~F} 6)$

This first 'modeling' or 'equation-fitting' generated one row of coefficients for each respondent in the study. Although the specific elements in each vignette differed because of the permuted design, the structure of the data remains the same for each row, namely the additive constant, and one coefficient for each of the 36 elements.

A hallmark of Mind Genomics is the discovery of different clusters, mind-sets. The mind-sets are groups of respondents, who look at a common topic (viz., restaurants) in different ways. The respondents are not necessarily defined by WHO the respondent is or what the respondent DOES, but rather by the pattern of the responses to the specific elements. The 36 coefficients (but not the additive constant) are used to create these different groups, called mind-sets.

The mind-sets are created by a clustering program known as $\mathrm{k}$-means clustering (Likas, 2003). It is the pattern of coefficients which is important, not any single coefficient. The k-means clustering program creates a measure of 'distance' between two respondents by using the 36 coefficients generated by each respondent. Distance between any pair of respondents is defined by the quantity (1-Pearson R), where the Pearson $\mathrm{R}$, a measure of relatedness of two sets of numbers, is computed from the 36 corresponding pairs of elements, the first from person $\mathrm{A}$, the second from person $\mathrm{B}$. The quantity (1-Pearson $\mathrm{R}$ ) ranges from a low of 0 when two patterns are parallel to each other, to a maximum of 2 when the two patterns are opposite to each other.

Clustering works in a purely mathematical way, independent of the meaning of the variables that it clusters. Human judgment is needed to select the number of clusters and to name the clusters. For Mind Genomics studies, the rule of thumb is to select as few clusters as possible (parsimony), subject to the fact that the clusters 'make sense', viz. tell a story (interpretability). A third rule, one more of caution than substance, is to select clusters of reasonable size, so that they are stable. When a cluster of small size emerges, this cluster can be pulled out and eliminated, as was done for MS2 for Bagel Shop, which interpretable, but too small to be stable, comprising only six respondents.

Step 5: Rerun the OLS Regression for Each Subgroup, Incorporating the Data from the Respondents Who are Assigned to the Subgroup by the k-Means Clustering Program

For the Total Panel, this means incorporating everyone. For the other subgroups, the clusters (now called mind-sets), this means running the OLS regression with the smaller number of respondents, viz., those who had been assigned to the mind-set.

\section{Step 6: Create the Equations for Each Feeling}

For each study separately, and using the data from the Total Panel, run the five separate regressions, one for each emotion. This time do not use the additive constant, so the equation estimated is 'forced through the origin. The expression is: Feeling $=\mathrm{k}_{1}(\mathrm{~A} 1)+\mathrm{k}_{2}(\mathrm{~A} 2) \ldots \mathrm{k}_{36}(\mathrm{~F} 6)$

\section{Results}

\section{Interest in the Restaurant - The Bagel Shop vs. the Steak} House

The Mind Genomics cartographies return with large amounts of data, especially when the respondent is presented with 48 vignettes and instructed to rate each vignette on two scales. To make the analysis easy, we present only those coefficients of value +10 or higher. These are the elements which strongly drive the response of 'likely to visit'. For the additive constant we present the value emerging from the OLS regression, no matter the sign or the magnitude.

Table 4 shows the data for the Bagel Shop, Table 5 shows the data for the steakhouse.

We focus on highlights only, to give a sense of the meaning of the results, both from a general perspective and from the perspective of key elements and implications.

1. Number of mind-sets. Each cartography started out with 50 respondents. The k-means clustering program was instructed to 'create' three mind-sets, using the specific mathematical criterion. Mind-Set 2 for the Bagel Shop comprised only six respondents, too few to show. We do not show it because the results are unstable with the low base size and may mislead.

2. The additive constant. The additive constant is the baseline, the readiness of a respondents to say I am likelyk to visit the restaurant. The additive constant is a purely computed parameter. The first 'reality' of the constant lies in the facts that it will be the base to which will be added the contributions of the elements, when the user creates a new message to advertise the restaurant. The second reality is that the additive constant gives a sense of the basic interest in the restaurant, in the absence of elements. High additive constants means that there is an innate interested in the restaurant, independent of the elements. Low and negative additive constants mean that there is no interest, so that it is the job of the elements to do all the work of convincing. 
Howard Moskowitz (2022) Bagels and Steak: A Mind Genomics Cartography of an 'Alpha vs. Omega' of Dining

Table 4: Strong performing elements for the Bagel Store (BS), for the Total Panel and for BS Mind-Sets 1 and 3. BS Mind-Set 2 comprised only six respondents, and is not shown.

\begin{tabular}{|c|c|c|c|c|}
\hline & Bagel Shop & $\overrightarrow{\overrightarrow{0}}$ & 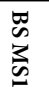 & 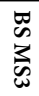 \\
\hline & Base Size & 50 & 26 & 18 \\
\hline & Additive constant & -1 & 12 & -33 \\
\hline & Bagel Shop MS1 & & & \\
\hline & THE BAGEL PURCHASE EXPERIENCE (BUT NOT NECESSARY EATING) & & & \\
\hline $\mathrm{C} 3$ & Get a free mug with a dozen bagels & 16 & 22 & \\
\hline $\mathrm{C} 5$ & Affordable prices & 16 & 22 & \\
\hline E6 & Free toasting available with spread purchase & 19 & 19 & 28 \\
\hline E3 & Mix and match for your favorite personal combination & 18 & 19 & 25 \\
\hline D6 & Innovative bagel technology to create the best taste & 24 & 18 & 42 \\
\hline E2 & All organic ingredients for the many spreads & 16 & 16 & 25 \\
\hline $\mathrm{C} 1$ & The best ingredients for the lowest prices & 18 & 13 & 25 \\
\hline D1 & Delicious in many flavors & 17 & 13 & 37 \\
\hline B1 & All bagels are highly nutritious & 13 & 13 & 20 \\
\hline C6 & Buy ten get two free & 13 & 12 & 13 \\
\hline F5 & Local delivery in only $30 \mathrm{~min}$ & 13 & 11 & 21 \\
\hline \multirow[t]{5}{*}{ A3 } & Convenient drive though & 10 & 11 & \\
\hline & Bagel Shop MS2 & & & \\
\hline & NOT SHOWN - ONLY SIX RESPONDENTS OUT OF 50 & & & \\
\hline & Bagel Shop MS3 & & & \\
\hline & FOCUS ON PRODUCT & & & \\
\hline D3 & Highest rated bagels in the state & 21 & & 57 \\
\hline D4 & Available in every flavor and color & 18 & & 47 \\
\hline D2 & Bagels are a high quality & 20 & & 45 \\
\hline $\mathrm{E} 4$ & Help create your own flavor with our new flavor creator & 14 & & 43 \\
\hline D5 & Savory and melts in your mouth & 23 & 10 & 42 \\
\hline D6 & Innovative bagel technology to create the best taste & 24 & 18 & 42 \\
\hline B4 & All bagels are made fresh & 16 & & 38 \\
\hline D1 & Delicious in many flavors & 17 & 13 & 37 \\
\hline $\mathrm{F} 2$ & Order one dozen bagels for only $\$ 6$ & 16 & & 32 \\
\hline B5 & No preservatives in our bagels & 13 & & 28 \\
\hline B2 & includes vitamins and minerals & & & 28 \\
\hline E6 & Free toasting available with spread purchase & 19 & 19 & 28 \\
\hline B6 & All spreads are healthy & 12 & & 26 \\
\hline $\mathrm{C} 1$ & The best ingredients for the lowest prices & 18 & 13 & 25 \\
\hline E2 & All organic ingredients for the many spreads & 16 & 16 & 25 \\
\hline E3 & Mix and match for your favorite personal combination & 18 & 19 & 25 \\
\hline A6 & Many locations available & 12 & & 22 \\
\hline F5 & Local delivery in only $30 \mathrm{~min}$ & 13 & 11 & 21 \\
\hline B3 & Bagels are all-organic & & & 20 \\
\hline F6 & Free shipping with any purchase over $\$ 15$ & 13 & & 20 \\
\hline B1 & All bagels are highly nutritious & 13 & 13 & 20 \\
\hline E5 & Hundreds of spreads to choose from & & 11 & 16 \\
\hline E1 & Made from high-quality ingredients & & & 14 \\
\hline C6 & Buy ten get two free & 13 & 12 & 13 \\
\hline F3 & Order before $6 \mathrm{pm}$ for same day shipping & & & 11 \\
\hline A4 & Comfortable ambience & & & 10 \\
\hline
\end{tabular}


Table 5: Strong performing elements for the Steak House (SH), for the Total Panel and Three Mind-Sets.

\begin{tabular}{|c|c|c|c|c|c|}
\hline & & $\overrightarrow{\underline{\theta}}$ & 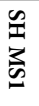 & \begin{tabular}{l} 
岕 \\
3 \\
\multirow{N}{*}{}
\end{tabular} & 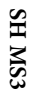 \\
\hline & Base size & 50 & 12 & 11 & 27 \\
\hline & Additive constant: & 57 & 67 & 47 & 57 \\
\hline & Mind-Set 1 - Food Quality & & & & \\
\hline A5 & Zagat rating of best beef wellington in the city & & 14 & & \\
\hline \multirow[t]{2}{*}{ A6 } & All our food is cooked with fresh grown material and all our steaks are USDA prime approved steaks & & 11 & & \\
\hline & Mind-Set 2 -Selection and Service & & & & \\
\hline $\mathrm{C} 4$ & Enjoy a drink while you wait for your table & & & 18 & \\
\hline D1 & Located in the heart of the city & & & 17 & \\
\hline C6 & Since opening our restaurant has been rated top in the city for cleanliness & & & 12 & \\
\hline A3 & Come try our legendary $48 \mathrm{oz}$ porter house and join the carnivore club & & & 12 & \\
\hline A2 & Our menu includes more than just steaks...variety of delicious chicken, fish and vegetarian options & & & 11 & \\
\hline \multirow[t]{2}{*}{ B2 } & Our staff offers service with a smile & & & 11 & \\
\hline & Mind-Set3 - Decor & & & & \\
\hline E5 & Fresh flowers on each table to satisfy your senses & & & & 14 \\
\hline E1 & Going on a date...enjoy our quiet child-free sections after 9 p.m. & & & & 13 \\
\hline E2 & Lightly colored rooms to satisfy eloquent dining & & & & 12 \\
\hline
\end{tabular}

Bagel Shop (Table 4): Basic interested in the restaurant without specifics is virtually nil (-1). Mind-Set 1 has a minimal positive response; Mind-Set 2 has a negative response to the idea of the Bagel Shop. In both cases it will be the elements which will drive the response of 'likely to visit'.

Steak House (Table 5): Basic interest in the restaurant is medium to high, very high for Mind-Set 1 (67).

The data suggest clear differences in the mind of the respondent who thinks about these two restaurants in terms planning to visit the restaurant. It may be that one simply does not plan to 'visit' a bagel shop in the same way that one visits a steak house.

3. The strong performing coefficients for the Total Panel. Most Mind Genomics studies reveal a few elements performing strongly, with 'strongly' defined operationally as 10 or higher when the model has an additive constant, and when the rating is assigned to one scale (viz. likely to visit, or degree of interest). The data from our two restaurants will show a major difference in the patterns for Total Panel

Our two restaurants differ dramatically for the coefficients for the total panel. Skipping to the steak house first, we see no strong elements with coefficients over 10 for the steakhouse (Table 5).

Returning now to the Bagel Shop (Table 4), we see a remarkable 14 of 36 elements with coefficients of 16 or higher, a record number in the informal history of Mind Genomics

Innovative bagel technology to create the best taste

Savory and melts in your mouth

Highest rated bagels in the state

Bagels are a high quality

Free toasting available with spread purchase

Mix and match for your favorite personal combination
The best ingredients for the lowest prices

Available in every flavor and color

Delicious in many flavors

Get a free mug with a dozen bagels

Affordable prices

All organic ingredients for the many spreads

All bagels are made fresh

Order one dozen bagels for only $\$ 6$

1. Define the mind-sets. The statistical method of clustering does not name the clusters. Naming the cluster is the task of the researcher. The usual criterion for naming the cluster or mindset is by identifying the 'story' linking the strongest messages. There need not be a single theme, especially in multi-attribute situations such as restaurants, where the elements come from a variety of sources (product, service, ambience, prices).

Bagel Shop Mind-Set 1 responds both to the experience of buying a bagel, and then to some aspects of the eating experience.

Bagel Shop Mind-Set 2 is not shown because it comprised only six respondents.

Bagel Shop Mind-Set 3 has a remarkably low additive constant (-33) but responds to most of the elements. For Bagel Shop Mind-Set 3 , the drivers are first statements about the product/eating experience, and secondarily about the other aspect of the experience

For the Bagel Shop mind-sets, we can say that they intertwine product and non-product experiences..

Steak House Mind Set 1 focuses on quality.

Steak House Mind Set 2 focuses on selection and service

Steak House Mind Set 3 focuses on decor 
In contrast to the Bagel Shop, the Steak House mind-sets dramatically differ in their focus and cannot be confused. That is, for the Bagel Shop it is a matter of differentially weighting the same inputs to arrive at a decision. For the Steak House it is a matter of which description is most compelling.

\section{Linking Feelings to Elements}

Tables 6 and 7 show the linkage between the elements and the five feelings, done for the total panel for each study. Recall that the respondent selected a single feeling as a response to an entire vignette, the vignette comprising three or four elements. Thus, just as in Question \#1 (interest), it is virtually impossible for the respondent to consciously 'game the system,' unless the respondent selects only one, or at maximum two feelings from the set. The data suggest that for most feelings except Bored (Bagel Shop) or Intimidated (Steak House), all elements show strong linkages with feelings.

Table 6: Strong linkages between feelings and elements for Bagel Shop.

\begin{tabular}{|c|c|c|c|c|c|c|}
\hline & Bagel Shop & 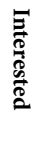 & 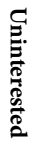 & 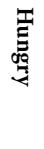 & 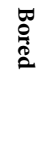 & $\begin{array}{l}\text { T. } \\
\text { 류. } \\
\text { م. }\end{array}$ \\
\hline & Interested & & & & & \\
\hline A2 & Convenient walking location & 21 & & & & \\
\hline A3 & Convenient drive though & 20 & & & & \\
\hline C3 & Get a free mug with a dozen bagels & 18 & & & & \\
\hline E2 & All organic ingredients for the many spreads & 18 & & & & \\
\hline $\mathrm{F} 2$ & Order one dozen bagels for only $\$ 6$ & 17 & & & & \\
\hline C6 & Buy ten get two free & 16 & & & & \\
\hline $\mathrm{C} 4$ & Gift cards available & 15 & 10 & & & \\
\hline Al & Easily available for commuters & 13 & & & & \\
\hline A6 & Many locations available & 13 & & & & \\
\hline C5 & Affordable prices & 12 & & & & \\
\hline D3 & Highest rated bagels in the state & 12 & & 10 & & \\
\hline E3 & Mix and match for your favorite personal combination & 12 & & & & \\
\hline $\mathrm{E} 4$ & Help create your own flavor with our new flavor creator & 12 & & & & \\
\hline A4 & Comfortable ambience & 11 & 11 & & & \\
\hline $\mathrm{C} 2$ & includes discounts & 10 & 11 & & & \\
\hline D1 & Delicious in many flavors & 10 & & & & \\
\hline E6 & Free toasting available with spread purchase & 10 & & & & \\
\hline \multirow[t]{2}{*}{ F3 } & Order before $6 \mathrm{pm}$ for same day shipping & 10 & 13 & & & \\
\hline & Uninterested & & & & & \\
\hline A5 & Nice music & & 13 & & & \\
\hline F3 & Order before $6 \mathrm{pm}$ for same day shipping & 10 & 13 & & & \\
\hline F6 & Free shipping with any purchase over $\$ 15$ & & 12 & & & \\
\hline A4 & Comfortable ambience & 11 & 11 & & & \\
\hline $\mathrm{C} 2$ & includes discounts & 10 & 11 & & & \\
\hline F4 & Order gift boxes for any occasion & & 10 & & & \\
\hline F5 & Local delivery in only $30 \mathrm{~min}$ & & 10 & & & \\
\hline \multirow[t]{2}{*}{$\mathrm{C} 4$} & Gift cards available & 15 & 10 & & & \\
\hline & Hungry & & & & & \\
\hline D5 & Savory and melts in your mouth & & & 20 & & \\
\hline B4 & All bagels are made fresh & & & 11 & & \\
\hline \multirow[t]{3}{*}{ E5 } & Hundreds of spreads to choose from & & & 11 & & \\
\hline & Bored - No strong linkages & & & & & \\
\hline & Excited & & & & & \\
\hline E5 & Hundreds of spreads to choose from & & & 11 & & \\
\hline
\end{tabular}


Table 7: Strong linkages between feelings and elements for Bagel Shop.

\begin{tabular}{|c|c|c|c|c|c|c|}
\hline & & 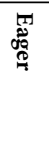 & $\begin{array}{l}\varrho \\
\stackrel{\partial}{0} \\
\stackrel{0}{\Xi}\end{array}$ & 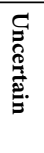 & 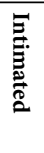 & 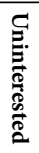 \\
\hline & Eager & & & & & \\
\hline A2 & Our menu includes more than just steaks...variety of delicious chicken, fish and vegetarian options & 12 & 11 & & & \\
\hline \multirow[t]{2}{*}{ A5 } & Zagat rating of best beef wellington in the city & 10 & & 10 & & \\
\hline & Confident & & & & & \\
\hline A6 & All our food is cooked with fresh grown material and all our steaks are USDA prime approved steaks & & 12 & & & \\
\hline B2 & Our staff offers service with a smile & & 12 & & & \\
\hline E4 & Start off your romantic evening with a candlelight dinner & & 12 & & & \\
\hline C6 & Since opening our restaurant has been rated top in the city for cleanliness & & 11 & & & \\
\hline A2 & Our menu includes more than just steaks...variety of delicious chicken, fish and vegetarian options & 12 & 11 & & & \\
\hline A1 & We have the biggest portion sizes around. & & 10 & 11 & & \\
\hline A4 & Many great desert options made from our world-renowned pastry chef & & 10 & & & \\
\hline \multirow[t]{2}{*}{ E6 } & Keep warm while waiting for your table near our fireplace & & 10 & & & \\
\hline & Uncertain & & & & & \\
\hline D2 & Conveniently located to subway lines & & & 18 & & \\
\hline D4 & Located near the financial sector of town & & & 18 & & \\
\hline C3 & Come eat at the bar each night 7-9 p.m. for our happy hour discounts & & & 16 & & \\
\hline B4 & We offer a private room for up to 50 guests & & & 15 & & 10 \\
\hline C5 & Get into the holiday spirit with our seasonal decorations & & & 14 & & \\
\hline D5 & Located a block away from the stadium & & & 14 & & 10 \\
\hline $\mathrm{C} 2$ & We offer a huge selection of aged wine & & & 13 & & \\
\hline $\mathrm{C} 4$ & Enjoy a drink while you wait for your table & & & 13 & & \\
\hline F5 & Learn how to cook like our chefs...come to a cooking class in the afternoons & & & 12 & & \\
\hline A1 & We have the biggest portion sizes around. & & 10 & 11 & & \\
\hline A3 & Come try our legendary $48 \mathrm{oz}$ porter house and join the carnivore club & & & 11 & & \\
\hline D6 & Conveniently located a half mile off the interstate & & & 11 & & \\
\hline F2 & Enjoy a steak while cheering on the home team & & & 11 & & \\
\hline F3 & Offers a dance floor to spice up the night & & & 11 & & 10 \\
\hline E3 & Dress comfortable while enjoying our casual dining & & & 10 & & \\
\hline \multirow[t]{3}{*}{ A5 } & Zagat rating of best beef wellington in the city & 10 & & 10 & & \\
\hline & Intimidated - No Strong Linkages & & & & & \\
\hline & Uninterested & & & & & \\
\hline B3 & For your convenience book any reservation online & & & & & 11 \\
\hline B4 & We offer a private room for up to 50 guests & & & 15 & & 10 \\
\hline D5 & Located a block away from the stadium & & & 14 & & 10 \\
\hline F3 & Offers a dance floor to spice up the night & & & 11 & & 10 \\
\hline
\end{tabular}

The most important feeling for Bagel Shop in this set of feelings is Interest, an intellectual response. The most important feelings for Steak House are Uncertain, then Confident, emotional responses

\section{Discussion and Conclusions}

Mind Genomics focuses on the topics of the everyday, from the point of specifics, looking at how people respond to the different aspects or dimensions of the topic. This simple comparison of two types of restaurants shows how much can be learned by simply charting out the responses to the different messages. What are often considered to be simply throw-away pieces of information about a situation, e.g., descriptions of the food, of the service, of the experience, become important information on which one can construct a deeper understanding of a situation relevant to everyday life.

The simple tools that were used, collection of messages from existing sources, creating different combinations and the scoring of 
those combinations on both an evaluation scale and on a fit-to-feeling sale provides remarkably deep information, both in the general pattern and in the specific score of the elements. There would be no way to predict that the bagel shop would generate so many strong positive, and not have a dramatic segmentation, where the steak restaurant would generate so few strong positives, show high basic interest, and be so strongly segmented.

The promise of Mind Genomics is not simply deeper knowledge of a specific restaurant, although that is a welcome outcome. Rather, the promise of Mind Genomics is the ability to create deep understanding of how people respond to the ordinary things of their lives, the ordinary situations of their lives. There is some of that in the ongoing surveys of well-being and other concerns, especially social issues, such as USA Facts, or the PEW Research Center. Companies commission extensive attitudes and practices studies for the product or service in which they are involved. Yet, for the former, ongoing surveys of a social nature, the topics are so broad that the surveys merely touch the surface and signal the emerge of problems where they may be but not the specifics of the problem. The latter, attitudes and practices, are done on an irregular basis and at the request of marketers in a company, with the focus on the particular issues of the moment. In other words, trends can be pieced together across years, if the data can be compared from year to year, often impossible first because companies are reluctant to part with their private data just as company policy, and second because the questions may change from year to year depending upon the business environment, and the internal politics of the company, and the momentary proclivities of those in charge of knowledge and 'insight..'

With the foregoing in perspective, it might well be possible to foresee a project in which the researcher deals with say 20 different types of restaurants, focusing simply on the question of evaluation (Question \#1 here, likelihood of visiting). The current Mind Genomics technology, publicly available simply for the processing cost, would require 20 studies each with 50 respondents, or 1000 respondents altogether. The respondents would be required to answer age, gender, and one additional classification question. The studies would deal with 16 elements, not 36 elements, and require a 3-4-minute study for each respondent, testing 24 vignettes (rather than the 48 vignettes teste here). The entire set of studies could be set up in 1-2 days, executed in one day, with results completely analyzed available 1-2 hours after the study has been launched. The cost on a per country basis for the full set of 20 studies would be approximately $\$ 200-\$ 300$ per restaurant type per country, country, or a total of $\$ 4,000-\$ 6,000$ for the full set of 20 studies, for 20 types of restaurants. (The only additional cost might be a nominal cost to translate the elements, and the respondent interface screen). The database of 20 studies, each the same in 20 countries, over 10 years, would comprise 4,000 studies. Happily, the data would comparable across country and across year, a virtual unique, easy-to create resource of great intellectual value, and of historic worth value to mankind.

\section{Acknowledgments}

The authors are grateful to the Queens College Fund for sponsoring these studies.
The late Steven Onufrey and Ms. Janna Kaminsky helped to execute the studies in Prof. Braun's Math 110 class.

Prof. Henderson was COO of Queens College, and spearheaded the adoption of Math 110 2010-2014.

\section{References}

1. Moskowitz HR, Gofman A (2007) Selling Blue Elephants: How to Make Great Products that People Want Before They Even Know They Want Them. Pearson Education.

2. Meltzer R, Schuetz J (2012) Bodegas or bagel shops? Neighborhood differences in retail and household services. Economic Development Quarterly 26: 73-94.

3. Goldberg DE, Wang L (1997) Adaptive niching via coevolutionary sharing. Genetic Algorithms and Evolution Strategy in Engineering and Computer Science 21-38.

4. Goodman M (2005) The rise and fall of the bagel. Harvard Review 28: 91-99.

5. Gofman A, Moskowitz H (2010) Isomorphic permuted experimental designs and their application in conjoint analysis. Journal of Sensory Studies 25: 127-145.

6. Moskowitz HR, Gofman A (2003) System and method for content optimization. United States Patent No. 6,663,215,B1 (Issued December 9, 2003).

7. Likas A, Vlassis N, Verbeek JJ (2003) The global k-means clustering algorithm. Pattern Recognition 36: 451-461.

\section{Citation:}

Moskowitz H, Braun M, Henderson S, Mazzio J (2022) Bagels and Steak: A Mind Genomics Cartography of an 'Alpha vs. Omega' of Dining. Psychol J Res Open Volume 3(5): 1-11. 